\title{
A Global Scale Scenario for Prebiotic Chemistry: Silica-Based Self- Assembled Mineral Structures and Formamide
}

\author{
Raffaele Saladino, ${ }^{* \dagger}$ Giorgia Botta $^{\dagger}$ Bruno Mattia Bizzarri, $^{\dagger}$ Ernesto Di Mauro, \\ and Juan Manuel Garcia Ruiz*,§

\begin{abstract}
${ }^{\dagger}$ Dipartimento di Scienze Ecologiche e Biologiche, Università della Tuscia, Via San Camillo De Lellis, 01100 Viterbo, Italy
${ }^{\ddagger}$ Istituto Pasteur-Fondazione Cenci Bolognetti c/o Dipartimento di Biologia e Biotecnologie “Charles Darwin”, University “Sapienza”, Piazzale Aldo Moro 5, Rome 00185, Italy

${ }^{\S}$ Laboratorio de Estudios Crystalográficos, Instituto Andauz de Ciencias de la Tierra, CSIC-Universidad de Granada, Avenida de las Palmeras 4, E-18100 Armilla, Granada, Spain
\end{abstract}

Supporting Information

\begin{abstract}
The pathway from simple abiotically made organic compounds to the molecular bricks of life, as we know it, is unknown. The most efficient geological abiotic route to organic compounds results from the aqueous dissolution of olivine, a reaction known as serpentinization (Sleep, N.H., et al. (2004) Proc. Natl. Acad. Sci. USA 101, 12818-12822). In addition to molecular hydrogen and a reducing environment, serpentinization reactions lead to high-pH alkaline brines that can become easily enriched in silica. Under these chemical conditions, the formation of selfassembled nanocrystalline mineral composites, namely silica/carbonate biomorphs and metal silicate hydrate (MSH) tubular membranes (silica gardens), is unavoidable (Kellermeier, M., et al. In Methods in Enzymology, Research Methods in Biomineralization Science (De Yoreo, J., Ed.) Vol. 532, pp 225-256, Academic Press, Burlington, MA). The osmotically driven membranous structures have remarkable catalytic properties that could be operating in the reducing organic-rich chemical pot in which they form. Among one-carbon compounds, formamide $\left(\mathrm{NH}_{2} \mathrm{CHO}\right)$ has been shown to trigger the formation of complex prebiotic molecules under mineral-driven catalytic conditions (Saladino, R., et al. (2001) Biorganic \& Medicinal Chemistry, 9, 1249-1253), proton irradiation (Saladino, R. et al. (2015) Proc. Natl. Acad. Sci. USA, 112, 2746-2755), and laser-induced dielectric breakdown (Ferus, M., et al. (2015) Proc Natl Acad Sci USA, 112, 657-662). Here, we show that MSH membranes are catalysts for the condensation of $\mathrm{NH}_{2} \mathrm{CHO}$, yielding prebiotically relevant compounds, including carboxylic acids, amino acids, and nucleobases. Membranes formed by the reaction of alkaline $(\mathrm{pH} 12)$ sodium silicate solutions with $\mathrm{MgSO}_{4}$ and $\mathrm{Fe}_{2}\left(\mathrm{SO}_{4}\right)_{3} \cdot 9 \mathrm{H}_{2} \mathrm{O}$ show the highest efficiency, while reactions with $\mathrm{CuCl}_{2} \cdot 2 \mathrm{H}_{2} \mathrm{O}, \mathrm{ZnCl}_{2}, \mathrm{FeCl}_{2} \cdot 4 \mathrm{H}_{2} \mathrm{O}$, and $\mathrm{MnCl}_{2} \cdot 4 \mathrm{H}_{2} \mathrm{O}$ showed lower reactivities. The collections of compounds forming inside and outside the tubular membrane are clearly specific, demonstrating that the mineral self-assembled membranes at the same time create space compartmentalization and selective catalysis of the synthesis of relevant compounds. Rather than requiring odd local conditions, the prebiotic organic chemistry scenario for the origin of life appears to be common at a universal scale and, most probably, earlier than ever thought for our planet.
\end{abstract}

$\mathrm{T}$ he geological period lasting from the accretion of the planet to 3.8 giga-anni $(\mathrm{Ga})$ is named the Hadean. This name refers to Hades, lord of the Underworld, because that period was thought to be under such infernal conditions as high volcanic activity, high temperature, and intense meteoritic impacts such that even the preservation of rocks was impeded. However, recent isotopic analyses of the zircon crystals found in the Australian localities of Mt. Narryer ${ }^{6}$ and Jack Hills ${ }^{7}$ have changed that view. These geochemical analyses demonstrated that water might have existed in the liquid state much earlier than currently believed. If the age of the Earth is calculated to be $4.55 \mathrm{Ga},{ }^{8}$ some of these zircon crystals show that water condensed on the rocks of the surface of the planet as early 150 million years later., ${ }^{9,10}$ Organic carbon chemistry was thus already plausible 4.4 billion years ago. On such a young planet, water should have condensed on ultramafic rocks, which consisted of a scarce variety of minerals, mostly olivine and pyroxenes of variable cationic composition. This geochemical scenario intrinsically triggered serpentinization on a global, planet scale. ${ }^{11}$ Serpentinization reactions entail a reductive environment rich in $\mathrm{H}_{2}$ and $\mathrm{CH}_{4}$, the latter formed upon reaction with $\mathrm{CO}_{2}$ outgassing from the inner mantle. ${ }^{12,13}$ The Fischer-Tropsch process should have driven chemical reactions, leading to the formation of further complex organic molecules. ${ }^{14,15}$ The above-described geological scenario of weathered olivine and pyroxene minerals covering the surface of the planet led to water pools of high $\mathrm{pH}$ (about 12) and, upon interactions with plagioclase, quartz, or other silica-rich rocks and minerals, high silica concentration. Under these

Received: March 23, 2016

Revised: April 26, 2016

Published: April 26, 2016 


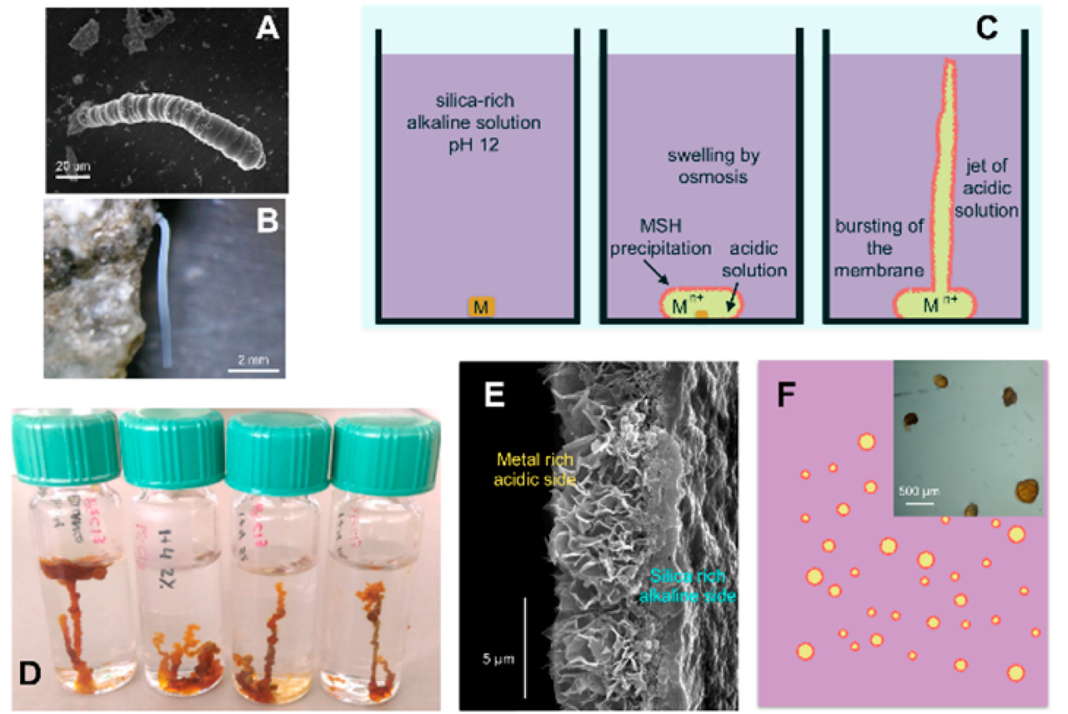

Figure 1. (A) Silica/barium carbonate biomorph. (B) Calcium silicate hydrate tubular membranes formed upon the interaction of a highly alkaline fluid with a granitic rock. ${ }^{20}$ (C) Interaction of a pellet of a soluble salt with a highly alkaline solution of silica produces the formation around the pellet of a thin membrane of metal silicate and hydroxides. The porous membrane works as a diaphragm, allowing the interchange of ions between the outer strongly alkaline silicate solution and the inner concentrated acidic solutions. ${ }^{18}$ Osmosis causes bursting of the membrane and injection of the inner solution into the outer one, which accounts for the formation of the tubular forms. (D) Iron silicate hydrate tubes formed in the presence of (from left to right) $0 \%, 2 \%, 5 \%$, and $10 \%(\mathrm{w} / \mathrm{w})$ formamide. (E) Cross section of the iron silicate hydrate membrane showing the textural and compositional gradient. (F) Iron silicate hydrate hollow microspheres formed by an acidic $\mathrm{FeCl}_{3}$ solution being sprayed in the alkaline sodium silicate solution, and a sketch of these structures expected to form in the early, lifeless planet is shown.

alkaline chemical conditions, silica is known to react with metals to form fascinating self-assembled mineral structures. At these $\mathrm{pH}$ values, barium, strontium, and/or calcium carbonate form silica biomorphs which are made by self-assembled carbonate nanocrystals, building textures of high complexity and showing morphologies with continuous curvature reminiscent of primitive living organisms and Precambrian microfossils (Figure 1A). ${ }^{16,17}$

In addition, the reaction of alkaline silica solution with metals such as zinc, iron, cobalt, magnesium, nickel, copper, etc., provokes the formation of a metal silicate hydrate (MSH) membrane and the spontaneous separation of two solutions with strong chemical differences. ${ }^{18}$ A morphogenetic mechanism based on a combination of osmosis, buoyancy, and chemical reaction results in hollow tubular architectures known as chemical gardens. Their osmotically driven formation and shape look so biological that they have long been linked to the origin of life, ${ }^{19}$ and more recently, they helped to develop a theory on the origin of life in white smokers. ${ }^{20,21}$ These MSH structures have been made in granitic rocks weathered by highly alkaline fluids $^{22}$ (Figure 1B), but their plausible role in prebiotic chemistry has never been tested. The catalytic role of minerals in the prebiotic synthesis of biologically relevant compounds from simple chemical precursors is well-known. ${ }^{23-25}$ The novelty and main interest that these self-assembled mineral structures bring to the search for mineral routes to life is twofold. First, the metal silicate hydrate phases have been shown to share the properties of a diaphragm and a membrane, displaying a textural and compositional gradient that allows selective catalytic properties of their inner and outer parts. Second, the membrane separates an enclosed volume of concentrated acidic metal salt solution from the surrounding strongly alkaline silica solution. The existence of an electrochemical potential difference of $20-120 \mathrm{mV}$ that lasts for several hours between the two compartments has been experimentally demonstrated. ${ }^{18}$ Finally, the metal silicate hydrate character of the membrane creates not only a compartmentalized volume but also a shield against ultraviolet radiation. $^{26}$

Among the plausible one-carbon atom chemical precursors that can be produced by purely geochemical pathways $(\mathrm{HCN}$, $\mathrm{HCOH}, \mathrm{HCOOH}, \mathrm{NH}_{2} \mathrm{CHO}$, and $\mathrm{HCOONH}_{4}$ ), we selected formamide for our experiments. Formamide $\left(\mathrm{NH}_{2} \mathrm{CHO}\right)$ has been shown to be highly active under mineral catalysis conditions. $^{3,4,27} \mathrm{NH}_{2} \mathrm{CHO}$ is largely diffused in the universe and has been detected in parsec-wide interstellar clouds. ${ }^{28,29}$ The fact that $\mathrm{NH}_{2} \mathrm{CHO}$ is liquid between 4 and $210{ }^{\circ} \mathrm{C}$ makes it particularly suited to concentration phenomena such as thermoconvection on rock. ${ }^{30}$ Space and terrestrial syntheses of $\mathrm{NH}_{2} \mathrm{CHO}$ under a large variety of conditions have been previously described and explained. $5,26,30$

\section{MATERIALS AND METHODS}

Formamide (Fluka, >99\%) was used without further purification. Fresh commercial water glass (Sigma-Aldrich, reagent grade, containing about 13.8 wt \% Na and 12.5 wt \% $\mathrm{Si}$ ) was used as the silica source and was further diluted 1/4 (v/ v) with Millipore water. We obtained silica gardens by dipping small pellets of a metal soluble salt into the (diluted) sodium silicate solution containing $2 \%, 5 \%$, or $10 \%$ (v/v) $\mathrm{NH}_{2} \mathrm{CHO}$ (see Figure 1 and Supplementary Video 1). Different metal soluble salts were used, namely, $\mathrm{ZnCl}_{2}, \mathrm{FeCl}_{2} \cdot 4 \mathrm{H}_{2} \mathrm{O}, \mathrm{CuCl}_{2}$. $2 \mathrm{H}_{2} \mathrm{O}, \mathrm{Fe}_{2}\left(\mathrm{SO}_{4}\right)_{3} \cdot 9 \mathrm{H}_{2} \mathrm{O}$, and $\mathrm{MgSO}_{4}$.

To model the chemical environment on the outer side of the tubular structures, $\mathrm{NH}_{2} \mathrm{CHO}(200 \mu \mathrm{L})$ was mixed with the sodium silicate solution $(2.0 \mathrm{~mL})$ in the presence of preformed MSH $\left[\mathrm{ZnCl}_{2}, \mathrm{FeCl}_{2} \cdot 4 \mathrm{H}_{2} \mathrm{O}, \mathrm{CuCl}_{2} \cdot 2 \mathrm{H}_{2} \mathrm{O}, \mathrm{Fe}_{2}\left(\mathrm{SO}_{4}\right)_{3} \cdot 9 \mathrm{H}_{2} \mathrm{O}\right.$, and $\left.\mathrm{MgSO}_{4}\right](2.0 \% \mathrm{w} / \mathrm{w})$ at $80{ }^{\circ} \mathrm{C}$ for $24 \mathrm{~h}$. In two selected cases $\left[\mathrm{FeCl}_{2}\right.$ and $\left.\mathrm{Fe}_{2}\left(\mathrm{SO}_{4}\right)_{3} \cdot 9 \mathrm{H}_{2} \mathrm{O}\right], \mathrm{NH}_{2} \mathrm{CHO}(200 \mu \mathrm{L})$ was mixed with the sodium silicate solution $(2.0 \mathrm{~mL})$ in the 
presence of selected growing MSH (starting from $2.0 \% \mathrm{w} / \mathrm{w}$ of the corresponding salt's pellet) at $80{ }^{\circ} \mathrm{C}$ for $24 \mathrm{~h}$. For the inner environment, $\mathrm{NH}_{2} \mathrm{CHO}(200 \mu \mathrm{L})$ was mixed with distilled water $(2.0 \mathrm{~mL})$ in the presence of selected $\mathrm{MSH}(2.0 \% \mathrm{w} / \mathrm{w})$ at $80{ }^{\circ} \mathrm{C}$ for $24 \mathrm{~h}$. The reaction of $\mathrm{NH}_{2} \mathrm{CHO}(10 \% \mathrm{v} / \mathrm{v})$ with the sodium silicate solution ( $\mathrm{pH} 12)$ without MSH membranes was also analyzed under similar experimental conditions. The products were analyzed by gas chromatography associated with mass spectrometry (GC-MS) after treatment with $\mathrm{N}, \mathrm{N}$ bis-trimethylsilyl trifluoroacetamide in pyridine $(620 \mu \mathrm{L})$ at 60 ${ }^{\circ} \mathrm{C}$ for $4 \mathrm{~h}$ in the presence of betulinol (CAS Registry Number 473-98-3) as the internal standard (0.2 $\mathrm{mg})$. Mass spectrometry was performed by the following program: injection temperature $280{ }^{\circ} \mathrm{C}$, detector temperature $280{ }^{\circ} \mathrm{C}$, gradient $100{ }^{\circ} \mathrm{C}$ for 2 $\mathrm{min}$, and $10^{\circ} \mathrm{C} / \mathrm{min}$ for $60 \mathrm{~min}$. To identify the structure of the products, two strategies were followed. First, the spectra were compared with commercially available electron mass spectrum libraries such as NIST (Fison, Manchester, U.K.). Second, GCMS analysis was repeated with standard compounds. All products have been recognized with a similarity index (SI) greater than $98 \%$ compared to that of the reference standards. The analysis was limited to products of $\geq 1 \mathrm{ng} / \mathrm{mL}$, and the yield was calculated as micrograms of product per starting formamide. For further experimental details, see the Supporting Information.

\section{RESULTS AND DISCUSSION}

We first demonstrated the formation of silica gardens in the presence of $\mathrm{NH}_{2} \mathrm{CHO}$. As shown in Figure $1 \mathrm{D}$ and

Table 1. Products Obtained (mg) after the Reaction of $\mathrm{NH}_{2} \mathrm{CHO}$ with Sodium Silicate Solution at Different Temperatures $^{a}$

\begin{tabular}{llll}
\multicolumn{1}{c}{ product } & \multicolumn{1}{c}{$25{ }^{\circ} \mathrm{C}$} & \multicolumn{1}{c}{$80{ }^{\circ} \mathrm{C}$} & \multicolumn{1}{c}{$120{ }^{\circ} \mathrm{C}$} \\
\hline guanidine (2) & traces & traces & traces \\
urea (3) & $1.0 \times 10^{-3}$ & $2.2 \times 10^{-3}$ & $0.5 \times 10^{-3}$ \\
pyruvic acid (4) & $1.1 \times 10^{-3}$ & $1.9 \times 10^{-3}$ & $0.3 \times 10^{-3}$ \\
lactic acid (5) & $0.7 \times 10^{-3}$ & $1.0 \times 10^{-3}$ & traces \\
glycolic acid (6) & traces & traces & \\
\hline
\end{tabular}

${ }^{a} \mathrm{NH}_{2} \mathrm{CHO}(200 \mu \mathrm{L})$ was mixed with the sodium silicate solution (2.0 $\mathrm{mL})$ at the reported temperatures for $24 \mathrm{~h}$. The data are the mean values of three experiments with standard deviations of less than $0.1 \%$.
Supplementary Video 1, metal silicate hydrate tubular structures can be formed readily in the presence of up to $10 \% \mathrm{NH}_{2} \mathrm{CHO}$ by small pellets of different metal soluble salts being dispensed inside a sodium silicate solution (SSS) containing $2 \%, 5 \%$, or $10 \%(\mathrm{v} / \mathrm{v}) \mathrm{NH}_{2} \mathrm{CHO}$ (see Methods). Then, we designed two different kinds of experiments to model the chemical environment in the outer and inner parts of the tubular structure according to previous work. In the first experiment, we dipped selected and preformed $\mathrm{MSH}$ tubules $\left[\mathrm{ZnCl}_{2}, \mathrm{FeCl}_{2} \cdot 4 \mathrm{H}_{2} \mathrm{O}, \mathrm{CuCl}_{2} \cdot 2 \mathrm{H} 2 \mathrm{O}, \mathrm{Fe}_{2}\left(\mathrm{SO}_{4}\right)_{3} \cdot 9 \mathrm{H}_{2} \mathrm{O}\right.$, or $\left.\mathrm{MgSO}_{4}\right]$ in an alkaline $(\mathrm{pH} 12)$ solution of sodium silicate containing $10 \%(\mathrm{v} / \mathrm{v}) \mathrm{NH}_{2} \mathrm{CHO}$. In two selected cases $\left[\mathrm{FeCl}_{2}\right.$ and $\left.\mathrm{Fe}_{2}\left(\mathrm{SO}_{4}\right)_{3} \cdot 9 \mathrm{H}_{2} \mathrm{O}\right]$, the first experiment was repeated in the presence of the membrane in growth by the addition of the pellets of soluble salts directly inside the sodium silicate solution. In the second experiment, we modeled the chemistry of the inner part of the tubular structures by dipping the selected $\mathrm{MSH}$ membrane in a water solution and $10 \%(\mathrm{v} / \mathrm{v})$ $\mathrm{NH}_{2} \mathrm{CHO}$. As a control experiment, we also analyzed the output of an alkaline solution ( $\mathrm{pH} \mathrm{12)}$ of sodium silicate with $\mathrm{NH}_{2} \mathrm{CHO}(10 \% \mathrm{v} / \mathrm{v})$ in the absence of MSH membranes. All of the experiments ran for $24 \mathrm{~h}$ at the optimized temperature of $80{ }^{\circ} \mathrm{C}$. The experiments were reproduced three times.

The results of the experiments are shown in Tables $1-3$ and Figure 2 (see also the Supporting Information). As a general trend, the control reaction at $80{ }^{\circ} \mathrm{C}$ afforded a panel of compounds larger than that obtained at 25 and $120{ }^{\circ} \mathrm{C}$. Guanidine (2), urea (3), pyruvic acid (4), lactic acid (5), and glycolic acid (6) were observed in small amounts (Table 1). The temperature of $80{ }^{\circ} \mathrm{C}$ was selected for the next reactions. The experiments that used preformed $\mathrm{MSH}$ membranes afforded a larger variety of products and did so in higher yields (Tables 2 and 3, respectively). In particular, the experiment modeling the catalytic effect of the outer side of the membrane afforded $2,3,4,5,6$, oxalic acid (7), succinic acid (8), malic acid (9), $N$-formylglycine (10), and diamino malonitrile (DAMN) (11) (Table 2 and Figure 2).

Similar results were obtained in the presence of the growing membrane (Table 2, data in parentheses), suggesting that the "active" silicate membranes do not play a key role when compared to that of preformed membranes.

Interestingly, the chemical environment modeling the inner side of the tubular structures afforded an even larger panel of products. In addition to compounds $2-11$, the inner

Table 2. Products Obtained after the Reaction of $\mathrm{NH}_{2} \mathrm{CHO}$ and SSS in the Presence of Selected $\mathrm{MSH}^{a}$

\begin{tabular}{|c|c|c|c|c|c|}
\hline product $^{b, c}$ & $\mathrm{ZnCl}_{2}$ & $\mathrm{FeCl}_{2}$ & $\mathrm{CuCl}_{2}$ & $\mathrm{Fe}_{2}\left(\mathrm{SO}_{4}\right)_{3}$ & $\mathrm{MgSO}_{4}$ \\
\hline guanidine (2) & & $0.90(0.40)^{d}$ & traces & $0.80(0.90)^{d}$ & traces \\
\hline urea $(3)^{c}$ & $2.0 \times 10^{-3}$ & $0.80(0.32)$ & 0.90 & $0.015(\mathrm{nd})^{e}$ & 0.01 \\
\hline pyruvic acid (4) & $1.9 \times 10^{-3}$ & $0.83(0.24)$ & traces & $0.15(0.05)$ & \\
\hline lactic acid (5) & 0.15 & $0.63(0.92)$ & traces & $0.16(0.11)$ & \\
\hline glycolic acid (6) & 0.11 & $0.01(0.12)$ & & traces & 0.11 \\
\hline oxalic acid (7) & $2.8 \times 10^{-3}$ & $0.18(\mathrm{nd})$ & & $0.38(0.25)$ & 0.12 \\
\hline succinic acid (8) & & & 0.16 & $0.096(0.01)$ & 0.071 \\
\hline malic acid (9) & & & & $0.02(0.06)$ & 0.005 \\
\hline$N$-formylglycine $(\mathbf{1 0})$ & $6.0 \times 10^{-3}$ & traces $(\mathrm{nd})$ & & $9.0 \times 10^{-3}(\mathrm{nd})$ & $2.3 \times 10^{-3}$ \\
\hline DAMN (11) & & $0.46(\mathrm{nd})$ & & $0.13(0.64)$ & 0.09 \\
\hline
\end{tabular}

${ }^{a} \mathrm{NH}_{2} \mathrm{CHO}(200 \mu \mathrm{L})$ was mixed with SSS $(2.0 \mathrm{~mL})$ in the presence of preformed MSH $(2.0 \% \mathrm{w} / \mathrm{w})$ at $80{ }^{\circ} \mathrm{C}$ for $24 \mathrm{~h} .{ }^{b} \mathrm{The}$ data are the mean values of three experiments with standard deviations of less than $0.1 \%$. ${ }^{c}$ The amount of product is defined as milligrams of compound compared to that of the initial reaction mixture. ${ }^{d} \mathrm{NH}_{2} \mathrm{CHO}(200 \mu \mathrm{L})$ was mixed with SSS $(2.0 \mathrm{~mL})$ in the presence of selected growing MSH (starting from $2.0 \%$ $\mathrm{w} / \mathrm{w}$ of the corresponding salt's pellet) at $80{ }^{\circ} \mathrm{C}$ for $24 \mathrm{~h}$. ${ }^{e} \mathrm{nd}=$ not determined. 
Table 3. Products Obtained after the Reaction of $\mathrm{NH}_{2} \mathrm{CHO}$ and Distilled Water in the Presence of Specific MSH ${ }^{a}$

\begin{tabular}{|c|c|c|c|c|c|c|c|}
\hline product $^{b}$ & $\mathrm{ZnCl}_{2}$ & $\mathrm{FeCl}_{2}$ & $\mathrm{CuCl}_{2}$ & $\mathrm{MnCl}_{2}$ & $\mathrm{Fe}_{2}\left(\mathrm{SO}_{4}\right)_{3}$ & $\mathrm{MgSO}_{4}$ & $\mathrm{CuN}_{2} \mathrm{O}_{6}$ \\
\hline guanidine $2^{c}$ & $5.2 \times 10^{-3}$ & $3.4 \times 10^{-3}$ & 1.6 & 0.1 & 0.18 & 0.12 & 0.67 \\
\hline urea 3 & traces & & 1.7 & $5.0 \times 10^{-3}$ & & traces & \\
\hline pyruvic acid (4) & $4.1 \times 10^{-3}$ & 0.01 & $1.8 \times 10^{-3}$ & & 0.73 & 0.7 & 0.28 \\
\hline lactic acid (5) & & & & & 0.07 & 0.05 & \\
\hline oxalic acid (7) & traces & & 0.10 & & traces & traces & \\
\hline succinic acid (8) & & & & & 0.21 & 0.17 & 0.18 \\
\hline malic acid (9) & & & & & 0.03 & 0.03 & \\
\hline$N$-formylglycine $(10)$ & 2.5 & 0.85 & traces & & 1.9 & 1.8 & \\
\hline DAMN (11) & & & & & 0.02 & traces & \\
\hline glycine (12) & 0.03 & 0.23 & 0.76 & & 0.57 & 0.53 & \\
\hline alanine (13) & traces & traces & traces & & 0.27 & 0.23 & \\
\hline parabanic acid (14) & & & 0.59 & & & & 0.9 \\
\hline 4(3H)-Pyr $(15)$ & & & 5.6 & 0.3 & traces & traces & 0.05 \\
\hline 2,4-DAP (16) & & & 0.3 & 0.02 & 0.18 & 0.17 & traces \\
\hline $6(\mathrm{OH})-2,4-\mathrm{DAP}(17)$ & & & 0.3 & 0.06 & & & traces \\
\hline 2,4-DAP-5COOH (18) & & & traces & & traces & traces & 0.14 \\
\hline cytosine (19) & & traces & 0.13 & & 0.18 & 0.15 & 1.2 \\
\hline isocytosine (20) & & traces & 5.0 & & 0.11 & 0.11 & 1.4 \\
\hline uracil (21) & traces & & 3.8 & 0.03 & 0.22 & 0.23 & 0.85 \\
\hline adenine (22) & & & 0.01 & & 0.01 & 0.01 & traces \\
\hline
\end{tabular}

${ }^{a} \mathrm{NH}_{2} \mathrm{CHO}(200 \mu \mathrm{L})$ was mixed with water $(2.0 \mathrm{~mL})$ in the presence of selected $\mathrm{MSH}(2.0 \% \mathrm{w} / \mathrm{w})$ at $80{ }^{\circ} \mathrm{C}$ for $24 \mathrm{~h} .{ }^{b}$ The data are the mean values of three experiments with standard deviations of less than $0.1 \% .{ }^{c}$ The amount of product is defined as milligrams of compound compared to that of the initial reaction mixture.

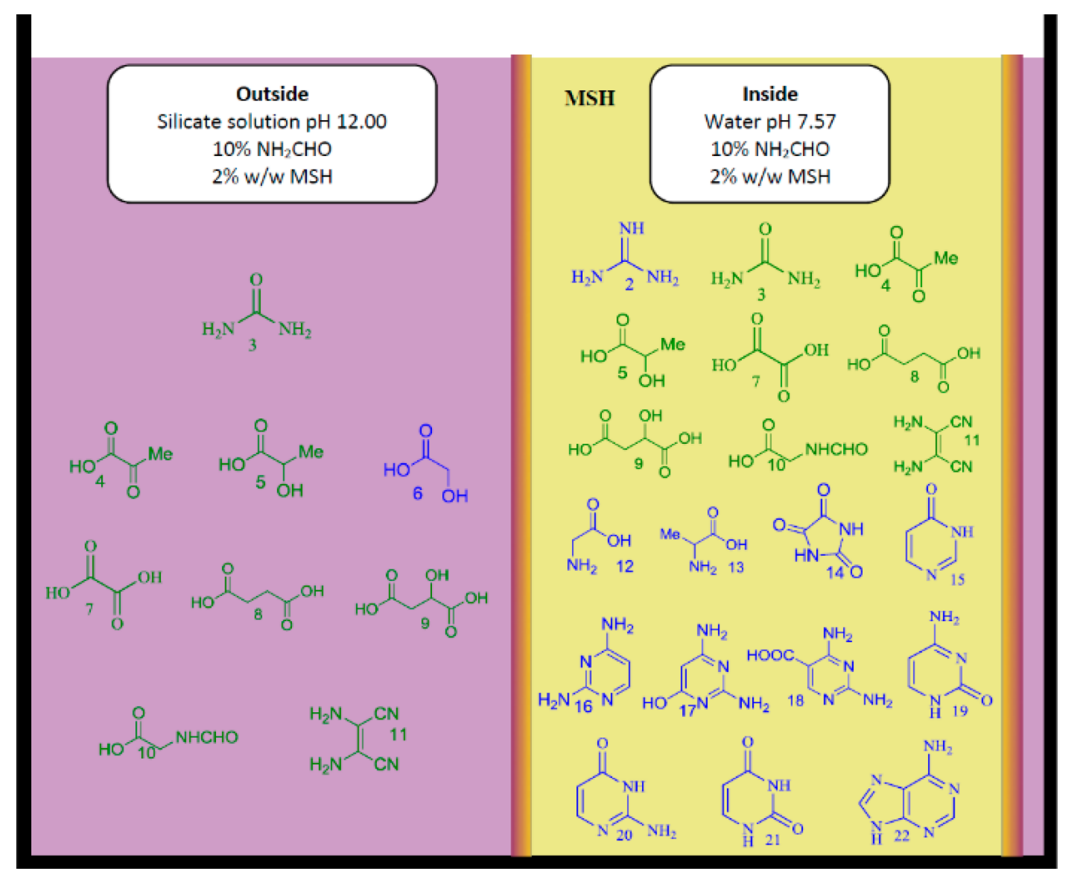

Figure 2. Schematic representation of products obtained with different $\mathrm{MSH}$ from $\mathrm{NH}_{2} \mathrm{CHO}$ outside (left) and inside (right) of the membranous structure. Color codes: compounds synthesized at both sides of the membrane (green); compounds synthesized only inside the membrane (blue).

environment of the membranes also catalyzed glycine (12), alanine (13), parabanic acid (14), 4(3H)pyrimidinone $[4(3 H)$ Pyr] (15), 2,4-diamino pyrimidine (2,4-DAP) (16), 6-hydroxy2,4-diamino pyrimidine [6(OH)-2,4-DAP] (17), 2,4-diamino pyrimidine-5-carboxylic acid (2,4-DAP-5COOH) (18), cytosine (19), isocytosine (20), uracil (21), and adenine (22) (Table 3 and Figure 2). $\mathrm{MgSO}_{4}, \mathrm{Fe}_{2}\left(\mathrm{SO}_{4}\right)_{3} \cdot 9 \mathrm{H}_{2} \mathrm{O}, \mathrm{CuN}_{2} \mathrm{O}_{6}$. $3 \mathrm{H}_{2} \mathrm{O}$, and $\mathrm{CuCl}_{2} \cdot 2 \mathrm{H}_{2} \mathrm{O}$ were the most active $\mathrm{MSH}$ in the synthesis of nucleobases 19, 21, and 22. Amino acids 12 and 13 were also produced in acceptable amounts
It is interesting to note that the salts of the two metals that form the olivine solid solution, $\mathrm{MgSO}_{4}$ and $\mathrm{Fe}_{2}\left(\mathrm{SO}_{4}\right)_{3} \cdot 9 \mathrm{H}_{2} \mathrm{O}$, are the most efficient salts, while $\mathrm{CuCl}_{2} \cdot 2 \mathrm{H}_{2} \mathrm{O}, \mathrm{ZnCl}_{2}, \mathrm{FeCl}_{2}$. $4 \mathrm{H}_{2} \mathrm{O}$, and $\mathrm{MnCl}_{2} \cdot 4 \mathrm{H}_{2} \mathrm{O}$ showed a low reactivity. Carboxylic acids 4-9 were obtained in larger amounts in the outer environment with the exception of only $\mathrm{MgSO}_{4}$ and $\mathrm{Fe}_{2}\left(\mathrm{SO}_{4}\right)_{3}$. $9 \mathrm{H}_{2} \mathrm{O}$. Therefore, this process is selective in terms of mineral properties because different metal silicate hydrated membranes afford different panels of products. Even more interesting is the fact that the panels of compounds formed inside and outside 
the tubular membrane are specific, as shown in Figure 2. Thus, nucleobases $(19,21$, and 22), nucleobase bioisosteres (16 and $20)$, and nucleobase analogues $(15,17$, and 18$)$ are produced only inside the membrane (Figure 2). Amino acids 12 and 13 are also synthesized only inside the membrane.

Carboxylic acids 4-9 were obtained in the inner and outer environments. The prebiotic roles of $\mathrm{DAMN}^{31}$ and the nucleobase bioisosteres and analogues have been reviewed previously. ${ }^{32}$ The ability of formamide to trigger the synthesis of compounds representative of the major classes of prebiotic precursors in the presence of a number of minerals (including boron-, iron-, sulfur-, zircon-, titanium-, and phosphorus-based minerals, metal oxides of various types, and meteorites) has been previously shown to be particularly efficient under proton irradiation and the simulated impact of an extraterrestrial body. Our results provide the first example of a catalytic process endowed with (a) selective catalysis of the synthesis of biogenic relevant compounds by a textured membrane, (b) intrinsic compartmentalization ability, and (c) a shielding environment against ultraviolet radiation. Interestingly, in the reported experiments, the nucleic acid precursors were located on the inner side of the membranes. However, we have not found significant differences in either the number or the yield of biochemically relevant compounds when comparing the reactivities of active versus passive metal silicate hydrate membranes. This means that the electron voltage reported in previous silica garden ${ }^{18}$ experiments does not play a differential role in the catalysis of prebiotic compounds. The geological niche proposed here for the transition from inorganic to organic geochemistry, a silica-rich, alkaline, aqueous solution in contact with metal-bearing minerals in the presence of $\mathrm{NH}_{2} \mathrm{CHO}$, was highly plausible during the Hadean and Archean times. This niche was settled most likely as early as $4.4 \mathrm{Ga}$, i.e., almost one billion years earlier than the oldest putative remnants of life on our planet. Therefore, the existence of biological compounds such as carboxylic acids, amino acids, and nucleobases, or their carbon-like derivatives in Hadean zircon crystals or in Archean rocks, is rather plausible. It is worth noting that in these organic geoniches, silica biomorphs that mimic primitive organisms readily form in the presence of alkaline earth metals. ${ }^{16}$ This geological niche is not exclusive to our planet. It should also exist, or have existed, on Earth-like planets, meteorite parent bodies, and comets, as well as in the interstellar dust made of olivine that are or were in contact with enriched regions of $\mathrm{NH}_{2} \mathrm{CHO}$ in the universe. These results suggest that the conditions required for the synthesis of the molecular bricks from which life self-assembles, rather than being local and bizarre, seem to be universal and geologically conventional.

\section{ASSOCIATED CONTENT}

\section{S Supporting Information}

The Supporting Information is available free of charge on the ACS Publications website at DOI: 10.1021/acs.biochem.6b00255.

Detailed experimental conditions of the reactions, GCMS chromatograms, mass-to-charge ratio $(\mathrm{m} / \mathrm{z})$ value, and the abundance of mass spectra peaks of the products (PDF)

Video of growing silica gardens (AVI)

\section{AUTHOR INFORMATION}

\section{Corresponding Authors}

*E-mail: saladino@unitus.it.

*E-mail: juanma.garciaruiz@gmail.com.

\section{Author Contributions}

R.S., G.B., and B.M.B. performed the condensation experiments with formamide, and J.M.G.R. performed the silica garden experiments. E.D.M. and J.M.G.R. conceived the work. J.M.G.R., R.S., and E.D.M. analyzed the results and wrote the manuscript.

\section{Funding}

The research behind this work received funding from the European Research Council under the European Union's Seventh Framework Programme (FP7/2007-2013)/ERC Grant Agreement 340863.

\section{Notes}

The authors declare no competing financial interest.

\section{ACKNOWLEDGMENTS}

The Italian Space Agency (ASI) project "Esobiologia e Ambienti estremi: dalla chimica delle Molecola alla Biologia degli estremofili" and COST Action TD 1308 are acknowledged. J.M.G.R. acknowledges the help of Francisca Espinosa with the experiments. The CGA of the University of Tuscia is acknowledged.

\section{ABBREVIATIONS}

MSH, metal silicate hydrate; SSS, sodium silicate solution; DAMN, diamino malonitrile; [4(3H)-Pyr], 4(3H)pyrimidinone; (2,4-DAP), 2,4-diamino pyrimidine; $[6(\mathrm{OH})$ 2,4-DAP], 6-hydroxy-2,4-diamino pyrimidine; (2,4-DAP$5 \mathrm{COOH}), 2,4$-diamino pyrimidine-5-carboxylic acid

\section{REFERENCES}

(1) Sleep, N. H., Meibom, A., Fridriksson, T. H., Coleman, R. G., and Bird, D. K. (2004) H2-rich fluids from serpentinization: Geochemical and biotic implications. Proc. Natl. Acad. Sci. U. S. A. 101, 1281812822.

(2) Kellermeier, M., Glaab, F., Melero-García, E., and García-Ruiz, J. M. (2013) Experimental Techniques for the Growth and Characterization of Silica Biomorphs and Silica Gardens. In Methods in Enzymology, Research Methods in Biomineralization Science (De Yoreo, J., Ed.) Vol. 532, pp 225-256, Academic Press, Burlington, MA.

(3) Saladino, R., Crestini, C., Costanzo, G., Negri, R., and Di Mauro, E. (2001) A Possible prebiotic synthesis of purine, cytosine, and $4(3 \mathrm{H})$-pyrimidinone from formamide: implications for the origin of life. Bioorg. Med. Chem. 9, 1249-1253.

(4) Saladino, R., Carota, E., Botta, G., Kapralov, M., Timoshenko, G. N., Rozanov, A. Y., Krasavin, E., and Di Mauro, E. (2016) Meteoritecatalyzed syntheses of nucleosides and of other prebiotic compounds from formamide under proton irradiation. Origins Life Evol. Biospheres 112, 2746-2755.

(5) Ferus, M., Nesvorný, D., Sponer, J., Kubelík, P., Michalčíková, R., Shestivská, V., Sponer, J. E., and Civiš, S. (2015) High-energy chemistry of formamide: A unified mechanism of nucleobase formation. Proc. Natl. Acad. Sci. U. S. A. 112, 657-662.

(6) Froude, D. O., et al. (1983) Ion microprobe identification of 4,100 \pm 4,200 Myr-old terrestrial zircons. Nature 304, 616-618.

(7) Amelin, Y., Lee, D.-C., Halliday, A. N., and Pidgeon, R. T. (1999) Nature of the Earth's earliest crust from hafnium isotopes in single detrital zircons. Nature 399, 252-255.

(8) Dalrymple, G. B. (2001) The age of the Earth in the twentieth century: a problem (mostly) solved. In Geological Society, Vol. 190, pp 205-221, Special Publications, London. 
(9) Wilde, S. A., Valley, J. W., Peck, W. H., and Graham, C. M. (2001) Evidence from detrital zircons for the existence of continental crust and oceans on the Earth 4.4 Gyr ago. Nature 409, 175-178.

(10) Mojzsis, S. J., Harrison, T. M., and Pidgeon, R. T. (2001) Oxygen-isotope evidence from ancient zircons for liquid water at the Earth's surface 4,300 Myr ago. Nature 409, 178-181.

(11) Berndt, M. E., Allen, D. E., and Seyfried, W. E. (1996) Reduction of $\mathrm{CO}_{2}$ during serpentinization of olivine at $300{ }^{\circ} \mathrm{C}$ and 500 bar. Geology 24, 351-354.

(12) Schulte, M., Blake, D., Hoehler, T., and McCollom, T. M. (2006) Serpentinization and its implications for life on the early Earth and Mars. Astrobiology 6, 364-376.

(13) Neubeck, A., Duc, N. T., Bastviken, D., Crill, P., and Holm, N. G. (2011) Formation of $\mathrm{H} 2$ and $\mathrm{CH} 4$ by weathering of olivine at temperatures between 30 and $70^{\circ} \mathrm{C}$. Geochem. Trans. 12 (2011), 6 .

(14) McCollom, T. M., and Seewald, J. S. (2007) Abiotic synthesis of organic compounds in deep-sea hydrothermal environments. Chem. Rev. 107, 382.

(15) Lazar, C., McCollom, T. M., and Manning, C. E. (2012) Abiogenic methanogenesis during experimental komatiite serpentinization: Implications for the evolution of the early Precambrian atmosphere. Chem. Geol. 326-327, 102-112.

(16) García-Ruiz, J. M., Hyde, S. T., Carnerup, A. M., Christy, A. G., Van Kranendonk, M. J., and Welham, N. J. (2003) Self-Assembled Silica-Carbonate Structures and Detection of Ancient Microfossils. Science 302, 1194-1197.

(17) García-Ruiz, J. M., Melero-García, E., and Hyde, S. T. (2009) Morphogenesis of Self-Assembled Nanocrystalline Materials of Barium Carbonate and Silica. Science 323, 362-365.

(18) Glaab, F., Kellermeier, M., Kunz, W., Morallon, E., and GarcíaRuiz, J. M. (2012) Angew. Chem. 124, 4393-4397.

(19) Keller, E. F. (2002) Making Sense of Life: Explaining Biological Development with Models, Metaphors, and Machines, Harvard University Press, Cambridge, MA.

(20) Russell, M. J., Daniel, R. M., Hall, A. J., and Sherringham, J. A. J. (1994) J. Mol. Evol. 39, 231-243.

(21) Martin, W., and Russell, M. J. (2003) Philos. Philos. Trans. R. Soc., B 358, 59-85.

(22) Satoh, H., Tsukamoto, K., and García-Ruiz, J. M. (2014) Formation of chemical gardens on granitic rock: a new type of alteration for alkaline systems. Eur. J. Mineral. 26, 415-426.

(23) Bada, J. L. (2013) New insights into prebiotic chemistry from Stanley Miller's spark discharge experiments. Chem. Soc. Rev. 42, 2186-2196.

(24) Ruiz-Mirazo, K., Briones, C., and De La Escosura (2014) A. Prebiotic systems chemistry: New perspectives for the origins of life. Chem. Rev. 114, 285-366.

(25) Cleaves II, H. J., II, Scott, A. M., Hill, F. C., Leszczynski, J., Sahai, N., and Hazen, R. (2012) Mineral-organic interfacial processes: potential roles in the origins of life. Chem. Soc. Rev. 41, 5502-5525.

(26) Phoenix, V. R., Konhauser, K. O., Adams, D. G., and Bottrell, S. H. (2001) Role of biomineralization as an ultraviolet shield: Implications for Archean life. Geology 29, 823-826.

(27) Saladino, R., Botta, G., Pino, S., Costanzo, G., and Di Mauro, E. (2012) Genetics first or metabolism first? The formamide clue. Chem. Soc. Rev. 41, 5526-5565.

(28) Adande, G. R., Woolf, N. J., and Ziurys, L.-M. (2013) Observations of interstellar formamide: availability of a prebiotic precursor in the galactic habitable zone. Astrobiology 13, 439-453.

(29) Baaske, P., Weinert, F. M., Duhr, S., Lemke, K. H., Russell, M. J., and Braun, D. (2007) Extreme accumulation of nucleotides in simulated hydrothermal pore systems. Proc. Natl. Acad. Sci. U. S. A. 104, 9346-9351.

(30) Carota, E., Botta, G., Rotelli, L., Di Mauro, E., and Saladino, R. (2015) Current Advances in Prebiotic Chemistry Under Space Conditions. Curr. Org. Chem. 19, 1963-1979.

(31) Miller, S. L. (1986) Current status of the prebiotic synthesis of small molecules. Chemica Scripta 26B, 5-11.
(32) Saladino, R., Crestini, C., Pino, S., Costanzo, G., and Di Mauro, E. (2012) Formamide and the origin of life. Physics of Life Reviews 9, 84-104. 